\title{
Valence of distractor words increases the effects of irrelevant speech on serial recall
}

\author{
AXEL BUCHNER \\ Heinrich-Heine-Universität, Düsseldorf, Germany \\ KLAUS ROTHERMUND \\ Universität Trier, Trier, Germany \\ DIRK WENTURA \\ Friedrich-Schiller-Universität, Jena, Germany \\ and \\ BETTINA MEHL \\ Heinrich-Heine-Universität, Düsseldorf, Germany
}

\begin{abstract}
Participants memorized target words in silence or while ignoring neutral or valent (positive or negative) distractor words that could be either possessor-relevant or other-relevant. Distractor words impaired recall performance, but valent distractor words caused more disruption than neutral distractors, and negative distractors caused more disruption than positive distractors. The results are problematic for explanations of the irrelevant speech effect within working memory models that do not specify an explicit role of attention in the maintenance of information for immediate serial recall.
\end{abstract}

Immediate serial recall of short lists of visually presented items is impaired if irrelevant auditory stimuli are presented during either encoding or retrieval (Banbury, Tremblay, Macken, \& Jones, 2001). This phenomenon is typically referred to as the irrelevant speech effect or the irrelevant sound effect. The latter label takes into account that, contrary to earlier assumptions (Salamé \& Baddeley, 1982, 1987), acoustic characteristics other than speechlike properties determine the degree of disruption of serial recall performance. For instance, although vocal music has been found to be more disruptive than instrumental music (Salamé \& Baddeley, 1989), instrumental music with fast changes in amplitude and pitch may cause as much disruption as irrelevant speech (Klatte \& Hellbrück, 1993). Furthermore, random pitch glides interrupted regularly by silence are disruptive, whereas continuous pitch glides hardly affect serial recall, if they do at all (Jones, Macken, \& Murray, 1993), and a set of four different tones disrupts serial recall more than a single repeated tone (Jones \& Macken, 1993). Findings such as these have led to the conclusion that the degree of changing states inherent in the irrelevant material (an acoustic property that corresponds roughly to abrupt changes in amplitude and pitch) determines the size of the irrelevant speech effect (Jones, 1993; Jones, Beaman, \& Macken, 1996; Jones \& Tremblay, 2000). It fits with this assumption that in some

The research reported in this article was supported by Grant Bu 945/ 4-1 from the Deutsche Forschungsgemeinschaft. Correspondence concerning this article should be addressed to A. Buchner, Institut für Experimentelle Psychologie, Heinrich-Heine-Universität, D-40225 Düsseldorf, Germany (e-mail: axel.buchner@uni-duesseldorf.de). earlier studies neither the meaningfulness of irrelevant spoken words per se nor the semantic similarity between to-be-remembered visual items and auditory distractors affect serial recall performance (Buchner, Irmen, \& Erdfelder, 1996; Colle \& Welsh, 1976; Salamé \& Baddeley, 1982). However, Neely and LeCompte (1999) have demonstrated that in some sense the semantic similarity between targets and distractors may indeed play a role. Serial recall was reduced when distractor words were close semantic associates of the to-be-remembered target words. The data presented here show that in yet another sense the meaning of task-irrelevant auditory material may indeed have effects on serial recall performance.

Researchers using the Stroop task have shown that negative-trait adjectives delay the naming of the color in which they are printed more than do positive-trait adjectives, and valent words delay responding more than do neutral words, presumably by automatically attracting and consuming attention at the expense of resources available to concurrent cognitive processes (Pratto, 1994; Pratto \& John, 1991). The attention-grabbing effect may be particularly pronounced if valent words can be characterized as "other-relevant" (Wentura, Rothermund, \& Bak, 2000). This is plausible given that other-relevant traits denote unconditionally positive or negative consequences for persons in the social environment of the holder of the trait (e.g., friendliness, aggression; see Peeters, 1983), so that, for instance, other-relevant negative trait adjectives may serve as highly overlearned cues to potential threats in the environment that call for attention. In contrast, possessor-relevant traits (e.g., intelligence, depression; see Peeters, 1983) denote unconditionally positive or negative consequences for the 
trait holder, so that, although far from neutral, their attention-grabbing effect may be less pronounced. In essence, therefore, valent trait adjectives carry meaning in that they provide information about the trait holder herself or about the state of the environment that needs to be attended to. For the present purposes, it is important that valent information has indeed been shown to provoke automatic orienting of attention. The experiments reported here show that valent distractors, particularly other-relevant negative adjectives, impaired serial recall performance beyond the impairment caused by otherwise comparable neutral words.

Such findings have implications for theories of working memory that are used to explain the irrelevant sound effect. Elliott (2002) has argued that these theories fall into one of two categories: theories that explicitly specify a role for attention in the maintenance of information, and theories that instead assume that irrelevant sounds have automatic access to the representational structure that is also used for the primary task of maintaining a suitable representation of the to-be-recalled words.

A prominent theory that explicitly excludes a role for attention in the maintenance of information is Baddeley's modular working memory model (Baddeley, 1986, 1996; Baddeley \& Logie, 1999). According to Baddeley, the preferred strategy for the immediate serial recall of short visually presented word lists is to convert the words into an articulatory representational format so that they can be maintained in the limited-capacity articulatory loop module of working memory. Irrelevant auditory speech has been assumed to gain automatic access to this store, where it competes with the target representations, thereby impairing recall performance (Baddeley, 1986; Salamé \& Baddeley, 1982, 1989). The important point for the present purposes is that the model implies that the impairment occurs in a working memory structure in which the representational format is assumed to be acoustic or phonological, which is why semantic distractor properties such as the valence of to-be-ignored words must not affect serial recall performance. In addition, the model precludes a role for attention in the maintenance of information, in that the component identified with attentional function is the so-called central executive, and this component is assumed not to be involved in temporary storage (see, e.g., Baddeley \& Logie, 1999, p. 28). In sum, this model predicts that attentional distraction due to the valence of nominally irrelevant items must not occur.

The predictions are similar for the object-oriented episodic record model (Jones, 1993; Jones \& Macken, 1993; Jones \& Tremblay, 2000), the greatest strength of which is that it can easily explain the changing state effect. The model assumes that the crucial process in immediate serial recall is that of seriation of the to-be-recalled objects. These objects are temporarily assembled on a structure referred to as a blackboard, on which they are linked by a series of production rules. Internal representations of to-berecalled visual items and the links interconnecting them are constructed by means of articulation. Once the items are represented on the blackboard, their modality of origin is no longer available. Auditorily presented information is parsed into objects by preattentive segmentation processes. Roughly, the more changing states there are in the auditory signal, the more different objects will be formed (up to a limit). Irrelevant auditory material disrupts serial recall of visual items because a set of competing links is established automatically among auditory distractor objects, and these links interfere with those for the visual targets. It is important, then, that impairment of serial recall performance stems from a loss of link integrity, not of item integrity. If a link to an item is lost, the item is no longer available for recall. Given that the valence of distractor words is definitely a nonacoustic property and thus is independent of the changing state property of the auditory signal, it should not affect serial recall performance.

Within the integrated-memory-and-attention framework suggested by Cowan $(1995,1999)$, working memory is viewed from a functional rather than a structural perspective. Working memory is defined by the set of cognitive processes that are needed to retain information represented in memory in a highly accessible state. The focus of attention represents the most highly activated subset of elements in working memory. In immediate recall tasks, the rehearsed target elements represent the focus of attention. Irrelevant sounds may automatically attract attention, thereby recruiting processing resources away from the currently attended object representations. A reduction of attention available for rehearsing the target elements reduces their activation levels and, hence, the probability of successful recall of the visual targets. Within this framework, the type of auditory distractor could potentially affect serial recall performance if one type of distractors recruited more attention, leaving fewer resources for the rehearsal processes that constitute the current focus of attention. Pratto (1994) concluded that if a task requires much attention, then automatic evaluation of valent distractor content can hurt performance by taking attention. Rehearsal of supraspan word lists certainly is very attention demanding. Thus, valent spoken distractor words should impair recall more than neutral distractor words within this framework.

The feature model (Nairne, 1990; Neath, 2000) allows one to derive predictions that are similar to those derived from Cowan's $(1995,1999)$ working memory model because it includes an attentional parameter that can be changed to reflect the amounts of processing resources available for the memorization tasks (see Elliott, 2002). This parameter is used, for instance, to model the typically greater disruption of serial recall by articulatory suppression than by irrelevant speech. In terms of the mechanisms that cause the performance decrements (to be discussed in the next paragraph), articulatory suppression and irrelevant speech are assumed to be equivalent, but more effort is presumably required to actively produce the distractors in the articulatory suppression condition than merely to listen to them in the irrelevant speech condition. Thus, it may be assumed that less attention is available for the primary task in the articulatory suppression than in the irrel- 
evant speech condition, which is modeled by adjusting the attentional parameter. A similar assumption could be made with respect to the processing of auditory distractor words. If the processing of valent words attracted more of a finite attentional resource than the processing of neutral words, then ignoring the former type of distractor words should leave relatively less attention for the memorization task, resulting in reduced serial recall performance. This, too, could be modeled by adjusting the attentional parameter appropriately.

The present experiments allow us to perform an additional test of the feature model, which predicts that irrelevant speech should not interact with serial position (Neath, 2000). It is assumed that the features of the irrelevant sounds overwrite a certain number of elements of the feature vectors of the target representations in working memory so that these representations become even more degraded than they normally would be. A reduction in the number of intact features reduces the probability of successfully matching a degraded representation from working memory to a long-term memory representation. A successful match is a prerequisite for successful recall; hence the reduced recall performance when irrelevant distractors add to the degrading of representations in working memory. Importantly, feature overwriting occurs irrespective of the serial position of the target item. Thus, if irrelevant speech reduces recall performance, it must do so uniformly across all serial positions. In terms of a statistical hypothesis this means that serial position and irrelevant speech variables must not interact.

\section{EXPERIMENT 1}

\section{Method}

Participants. The participants were 64 students ( 40 women) who were paid for their participation. Their ages ranged from 19 to 45 years $(M=24)$. Each participant was tested individually.

Materials. The participants wore headphones that were plugged directly into an Apple iMac computer, which controlled the experiment. Sounds were produced at a level of about $75 \mathrm{~dB}(\mathrm{~A})$.

The target words to be memorized were seven three-syllable nouns (Bilderbuch [picture-book], Hutschachtel [hat box], Kalender [calendar], Laterne [lantern], Obstschale [fruit bowl], Pullover [sweater], and Tannenbaum [fir tree]) that were used for all experimental conditions (see below). For every experimental sequence, six of these seven words were sampled randomly without replacement for presentation.

The irrelevant distractor words were three-syllable trait adjectives. The distractor adjectives were spoken by a female voice and were digitally recorded at $44.1 \mathrm{kHz}$ using 16-bit encoding. Each word was edited to last $700 \mathrm{msec}$ and was normalized so as to minimize amplitude differences among the words. Each of these auditory distractors was presented binaurally in parallel to the 700-msec visual display of a target noun. There were five types of distractor adjectives: neutral, positive and possessor-relevant, positive and otherrelevant, negative and possessor-relevant, and negative and otherrelevant (Peeters, 1983). The words were a subset of those used by Wentura et al. (2000). Valence and concreteness of the distractor adjectives were taken from published norms (Hager, Mecklenbräuker, Möller, \& Westermann, 1985; Möller \& Hager, 1991) and are reported in Table A1 of the Appendix along with the frequencies of the words in the language, which was determined using the German lan- guage corpus available in the CELEX database (Centre for Lexical Information, 1991). The goal was to arrive at one neutral, two positive (possessor-relevant and other-relevant), and two negative (possessor-relevant and other-relevant) word sets, with a minimal difference between the word sets on other characteristics that might possibly affect how distracting they could be (e.g., number of syllables, concreteness, frequency). These five word sets, together with a silent control condition, defined the six experimental conditions of this experiment.

Procedure. The experiment began with three practice sequences during which six visually presented two-syllable training words had to be remembered for immediate verbal serial recall. Each target word was presented for $700 \mathrm{msec}$. Following a $500-\mathrm{msec}$ retention interval, the words had to be recalled in the order in which they had been presented. The participants responded with the German analog to the word "blank" for each word they could not recall. The participants' responses were recorded by a tape recorder for later evaluation.

The 48 experimental sequences were parallel to the training sequences but consisted of six visually presented target words that were randomly drawn without replacement from the seven threesyllable target words. Sets of eight sequences of target words were presented (1) in silence, (2) accompanied by neutral distractor adjectives, (3) accompanied by positive possessor-relevant distractor adjectives, (4) accompanied by positive other-relevant distractor adjectives, (5) accompanied by negative possessor-relevant distractor adjectives, and (6) accompanied by negative other-relevant distractor adjectives. Each of these six sets of eight sequences defined one experimental condition. The succession of sequences from the six different experimental conditions was random.

On average, the experiment lasted about $40 \mathrm{~min}$, after which the participants were offered an explanation as to its purpose.

Design. The within-subjects independent variables were distractor type (silence, neutral distractors, positive possessor-relevant distractors, positive other-relevant distractors, negative possessorrelevant distractors, and negative other-relevant distractors) and serial position. The dependent variable was the participants' serial recall performance - that is, the number of visually presented words recalled at the serial position at which they were presented.

Given a total sample size of $N=64, \alpha$ set to .05 , and the assumption that the average population correlation between the levels of the repeated measures factor is $\rho=.4$ (estimated from pilot data), effects of size $f=0.2$ (i.e., somewhat smaller than "medium" effects as defined by Cohen, 1977) could be detected for the global distractor type variable with a probability of $1-\beta=.95 .{ }^{1}$ In binary comparisons of two levels of the distractor type variable or in one of the orthogonal contrasts on this variable, effects of size $d_{\mathrm{z}}=0.4$ (see Cohen, 1977) could be detected with a probability of $1-\beta=.94$. The level of $\alpha$ was set to .05 for all the analyses reported in this article. Partial $R^{2} \mathrm{~s}$ are reported as a measure of the size of an effectthat is, the amount of variance explained relative to the variance not explained by other variables (see Cohen, 1977).

\section{Results}

Figure 1 illustrates the serial recall performance in all six experimental conditions. A $6 \times 6$ repeated measures multivariate analysis of variance (MANOVA) with distractor type and serial position as independent variables showed significant main effects of distractor type $[F(5,59)=$ $\left.27.10, p<.01, R_{\mathrm{p}}^{2}=.70\right]$ and of serial position $[F(5,59)=$ $\left.188.94, p<.01, R_{\mathrm{p}}^{2}=.94\right]$. The interaction between the two variables was also significant $\left[F(25,39)=1.84, R_{\mathrm{p}}^{2}=\right.$ $.54, p=.04]$.

We used orthogonal contrasts on the distractor type variable to test more specific hypotheses about the effects of the different distractor types. The first of these orthog- 


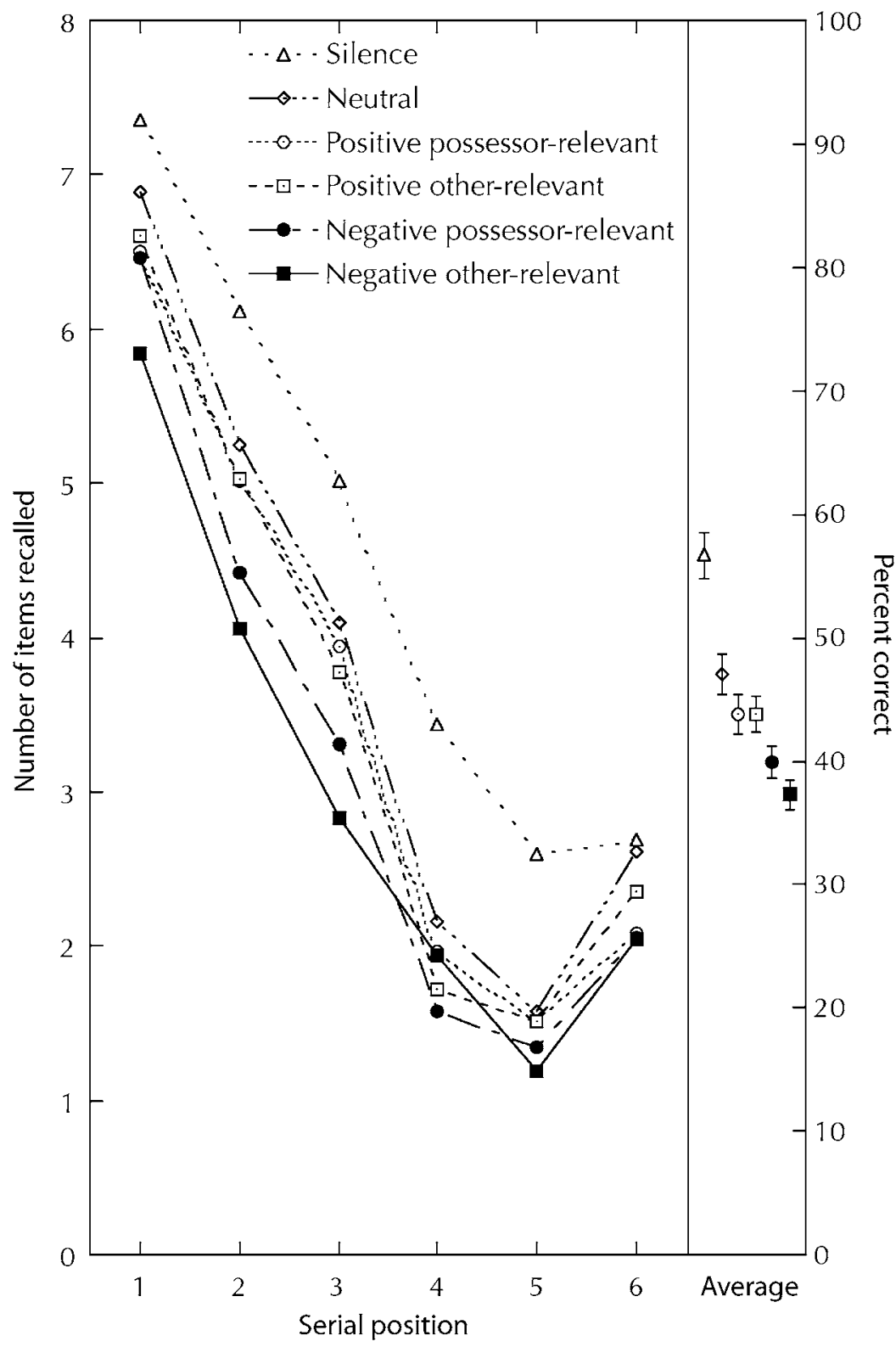

Figure 1. Cumulated number of words recalled correctly at each serial position (eight words at most; left panel) and percent correct averaged across serial positions (right panel) as a function of the distractor conditions in Experiment 1. The error bars represent the standard errors of the means.

onal contrasts showed that the difference between the silent control condition and all other conditions combined was significant $\left[F(1,63)=131.09, R_{\mathrm{p}}^{2}=.68, p<.01\right]$, confirming that there was a typical irrelevant speech effect. Second, the neutral distractors condition differed from the other conditions with auditory distractors $[F(1,63)=24.10$, $\left.R_{\mathrm{p}}^{2}=.28, p<.01\right]$, showing that valent distractors caused more disruption in serial recall than did neutral distractors. Third, skipping the theoretically uninteresting contrast between the positive possessor-relevant distractors condition and the remaining three distractor conditions, we found that the positive other-relevant distractors caused less disruption in serial recall than did the two types of negative adjectives as distractors $\left[F(1,63)=17.49, R_{\mathrm{p}}^{2}=\right.$ $.22, p<.01]$. Together with the obvious finding that the positive possessor-relevant and positive other-relevant distractor conditions did not differ, it follows that negative distractors caused more disruption than did positive distractors. Finally, the difference between negative possessorrelevant and negative other-relevant distractors just missed 
the preset criterion for statistical significance in this twotailed test $\left[F(1,63)=3.76, R_{\mathrm{p}}^{2}=.06, p=.06\right]$. However, a one-tailed $t$ test could also be justified, in which case we would conclude that the difference was statistically significant.

When we looked at the decomposition of the serial position variable into orthogonal polynomial contrasts, we found that all trends - from the linear trend to the fifthorder trend-were statistically significant $[F(1,63) \geq$ $\left.8.48, R_{\mathrm{p}}^{2} \geq .12, p<.01\right]$. However, it was obvious that the linear and quadratic trends explained by far the largest amounts of variance of the serial position curve $[F(1,63)=$ $527.80, R_{\mathrm{p}}^{2}=.89, p<.01$ and $F(1,63)=159.74, R_{\mathrm{p}}^{2}=.72$, $p<.01$, respectively], so that it seemed justified to neglect the cubic, fourth-, and fifth-order trends when analyzing in more detail the effect underlying the global interaction between the distractor type and serial position variables. Thus, we focused on interactions between the orthogonal contrasts of the distractor type variable as described in the previous paragraph, and on the linear and quadratic trends of the serial position variable. The only significant effect was an interaction between (1) the variable contrasting the silent control condition with all distractor conditions combined (2) and the variable representing the quadratic trend of the serial position variable $[F(1,63)=$ $\left.16.40, R_{\mathrm{p}}^{2}=.21, p<.01\right]$. Thus, we may conclude that the major factor underlying the interaction between the distractor type and serial position variables was that the shape of the serial position curve captured by the quadratic trend was different for the silent control condition relative to all other conditions, which had auditory distractors. Specifically, inspection of Figure 1 suggests that the recall impairment caused by irrelevant speech is generally more pronounced at intermediate serial positions than at initial or final positions.

\section{Discussion}

Experiment 1 has shown that features other than the acoustic properties of irrelevant speech - the valence of the distractor words in the present case - may lead to a disruption of serial recall performance. Assuming that valent stimuli are behaviorally so relevant that they automatically attract attention, only models that allow for a specific role of attention in the maintenance of information seem to be able to explain the observed effects. Of those models, the feature model (Neath, 2000) seems to have problems with the interaction between the distractor type and the serial position variables. We will come back to this issue in the General Discussion section.

One could argue that the attracting of attention by valent words might differ qualitatively from the factors that normally cause the irrelevant speech effect. For instance, it could be assumed that valent stimuli lead to orienting reactions that impair the perception or initial processing of the to-be-remembered information, leading to weaker memory traces, which are less likely to be available for later serial recall. Broadbent (1983) has suggested that the irrelevant speech effect in general may be caused by a
Stroop-like attentional disruption of the intake of information. If indeed the attracting of attention by valent distractors simply served to reduce the quality of the representation in working memory, then the results of Experiment 1 would not speak to the validity of various explanations of the "typical" irrelevant speech effect. We therefore thought it important to test whether valent distractor adjectives would also disrupt serial recall if they are displayed only during a retention interval, in which case the intake and initial processing of the to-be-remembered visual information cannot be affected by any distractor properties.

\section{EXPERIMENT 2}

Experiment 2 was similar to Experiment 1 with the exception that auditory distractors were displayed either during encoding (as in Experiment 1) or during a retention interval (but not both) with identical delays between the presentation of the first target and retention for all conditions. Furthermore, only neutral and negative otherrelevant distractors were used in addition to the silent control condition.

\section{Method}

Participants. The participants were 69 students ( 47 women) who were paid for their participation. Their ages ranged from 19 to 35 years $(M=24)$. Each participant was tested individually.

Materials. The materials were identical to those used in Experiment 1 except that positive (possessor-relevant and other-relevant) and negative possessor-relevant auditory distractors were not used. Of the valent distractors, only the negative other-relevant distractors were used, because they had caused the largest performance disruption in Experiment 1. For the sake of brevity, they will be referred to as negative distractors from now on.

Procedure. The procedure was identical to that of Experiment 1 with the following exceptions. First, apart from the silent control condition, there were four distractor type conditions, defined by whether neutral or negative distractors were presented during encoding or retention. Encoding, but not retention, was accompanied by distractors in two distractor type conditions (neutral distractors during encoding and negative distractors during encoding). Retention, but not encoding, was accompanied by distractors in two additional distractor type conditions (neutral distractors during retention and negative distractors during retention). Second, the retention interval lasted for $4.2 \mathrm{sec}$ and was thus just as long as the encoding phase, during which six 700-msec target words were presented. On average, the experiment lasted about $45 \mathrm{~min}$.

Design. The within-subjects independent variables were distractor type (silence, neutral distractors during encoding, neutral distractors during retention, negative distractors during encoding, and negative distractors during retention) and serial position. The dependent variable was the participants' serial recall performance, as in Experiment 1.

Given a total sample size of $N=69, \alpha$ set to .05 and the assumption that the average population correlation between the levels of the repeated measures factor is $\rho=.4$, effects of size $f=0.2$ could be detected for the global distractor type variable with a probability of $1-\beta=.96$. The four distractor type conditions may also be viewed as composed of a $2 \times 2$ design with valence (neutral vs. negative) and distractor presentation (during encoding vs. during retention) as experimental variables. Comparisons of two levels of each of these variables are equivalent to comparisons of two levels of the distractor type variable (with the exception that twice as many data points 
are used to arrive at the subject-specific performance measure estimate) so that effects of size $d_{\mathrm{z}}=0.4$ (cf. Cohen, 1977) could be detected with a probability of $1-\beta=.95$ in these comparisons.

\section{Results}

Figure 2 illustrates the basic properties of the data. The performance level is generally lower than that observed in Experiment 1, which is to be expected given the longer retention interval in Experiment 2 (4.2 instead of $0.5 \mathrm{sec}$ ). Other than that, the results seem fairly similar. A $5 \times 6$ repeated measures MANOVA with distractor type and serial position as independent variables showed significant main effects of distractor type $\left[F(4,65)=8.16, R_{\mathrm{p}}^{2}=.33\right.$, $p<.01]$ and serial position $\left[F(5,64)=210.17, R_{\mathrm{p}}^{2}=.94\right.$, $p<.01]$. The interaction between both variables was also significant $\left[F(20,49)=1.92, R_{\mathrm{p}}^{2}=.44, p=.03\right]$. Of the orthogonal contrasts, only the one contrasting the silent control condition with the average of the four distractor type conditions was theoretically interesting. This contrast was significant $\left[F(1,68)=27.31, R_{\mathrm{p}}^{2}=.29, p<.01\right]$, confirming that there was a typical irrelevant speech effect.

As was mentioned in the Design section, the four distractor type conditions may also be conceived as a $2 \times 2$ design with valence (neutral vs. negative) and distractor

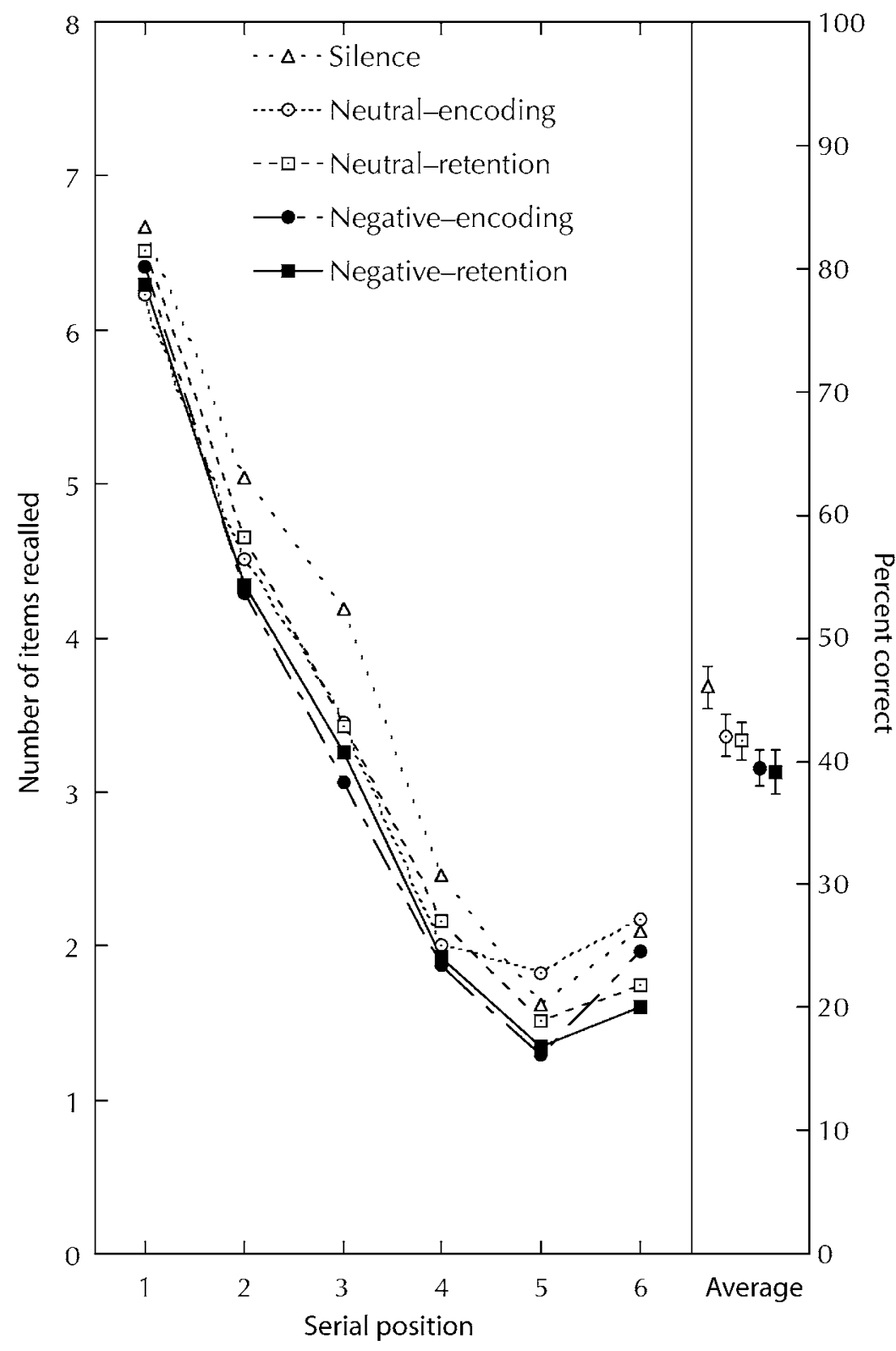

Figure 2. Cumulated number of words recalled correctly at each serial position (eight words at most; left panel) and percent correct averaged across serial positions (right panel) as a function of the distractor conditions in Experiment 2. The error bars represent the standard errors of the means. 
presentation (during encoding vs. during retention) as experimental variables. A $2 \times 2 \times 6$ MANOVA with these two as well as serial position as within-subject variables showed a main effect of valence $\left[F(1,68)=11.82, R_{\mathrm{p}}^{2}=\right.$ $.15, p<.01]$ and of serial position $[F(5,64)=174.63$, $\left.R_{\mathrm{p}}^{2}=.93, p<.01\right]$. The main effect of distractor presentation was not significant $\left[F(1,68)=0.10, p=.75, R_{\mathrm{p}}^{2}<\right.$ $.01]$, and neither was the interaction between valence and distractor presentation $\left[F(1,68)<0.01, p=.95, R_{\mathrm{p}}^{2}<\right.$ $.01]$. Also, none of the interactions involving the serial position variable was significant $\left[\right.$ all $F_{\mathrm{s}}(5,64)<1.52, R_{\mathrm{p}}^{2}<$ $.11, p>.20]$. We therefore conclude that the serial position curve is the same for all distractor conditions.

In Experiment 1, it was found that the global interaction between the distractor type and the serial position variable was due mainly to the fact that the shape of the serial position curve was different for the silent control condition relative to the conditions with auditory distractors. In Experiment 2 , the finding of a global distractor type $\times$ serial position interaction when the silent control condition was included, but not when only trials with auditory distractors were compared (see the previous two paragraphs), already suggests that the same conclusion may be drawn here. As an additional test, we looked at the interaction between the contrast variable comparing the silent control condition to all distractor conditions combined and the quadratic component of the serial position variable. This interaction had been significant in Experiment 1 and was statistically significant in Experiment 2 as well $[F(1,68)=6.35, p=.01$, $\left.R_{\mathrm{p}}^{2}=.09\right]$, suggesting that the global distractor type $\times$ serial position interaction has the same cause in both experiments. As in Experiment 1, it seems that the recall impairment caused by irrelevant speech is generally more pronounced at intermediate serial positions than at initial or final positions.

\section{Discussion}

The results of Experiment 2 complement those of Experiment 1 in showing that the disruptive effect of valent relative to neutral distractors is not due to attentional disruption at the level of perception and encoding of the targets, but rather to distraction during the maintenance of information in working memory for later serial recall. In addition, Experiment 2 confirmed the finding from Experiment 1 that irrelevant auditory distractors do not affect target items at all serial positions equally. As Neath (2000) has pointed out, this is problematic for the feature model's explanation of the irrelevant speech effect.

\section{GENERAL DISCUSSION}

Valent auditory distractors impaired serial recall of visually presented words more than did neutral distractors, and negatively valent distractors did so more than positive distractors. This was true particularly when the negative distractor adjectives were other-relevant, which is consistent with related results showing that negative otherrelevant stimuli represent the most potent distractor category (Wentura \& Rothermund, 2003). The impairment occurred irrespective of whether distractors were presented only during encoding or only during retention. This suggests that the present data reflect a decrement of memory processes and not one of processes related to perception. Thus, the present data are relevant for working memory models that have been used to explain the irrelevant speech effect.

The present data are unexpected given the assumptions of the modular working memory model (Baddeley, 1986, 1996; Baddeley \& Logie, 1999). According to this model, the task of maintaining lists of visually presented words for immediate recall is accomplished by converting the words into an articulatory representational format so that they can be maintained in the limited-capacity articulatory loop module of working memory. Attentional function is identified with the so-called central executive, and this working memory component is explicitly assumed not to be involved in temporary storage (see, e.g., Baddeley \& Logie, 1999, p. 28). Thus, attentional distraction by valent distractors is a phenomenon that this model cannot predict in its current state of development. The same conclusion holds for the object-oriented episodic record model (Jones, 1993; Jones \& Macken, 1993), which also does not specify a role for attention in the maintenance of information for immediate serial recall. In fact, an explicit specification of attentional functions is currently not contained in that model.

This is different for the modular working memory model, in which attentional functions are included in terms of the central executive. It follows that, in order to accommodate the present findings, one could drop the assumption that the central executive is not involved in temporary storage. In fact, Meiser and Klauer (1999) already suggested extending the modular working memory model by adding the auxiliary assumption that the central executive may contribute to performance in short-term retention tasks through the involvement of coordinative and supervisory functions. Meiser and Klauer showed that secondary tasks with high demands on central-executive processes interfered more with serial recall performance than did tasks with lower central executive demands. However, they observed larger decrements when attentional load was present during encoding than when it was present during retention. This feature does not map readily onto the pattern of results obtained in the experiments reported here. This difference may be due to the fact that the performance decrement in the experiments reported by Meiser and Klauer was caused by the requirement to perform secondary tasks, whereas the decrement in the present experiments was caused by irrelevant speech, which allows the participant to remain passive. A satisfactory explanation of this difference is beyond the purpose of the present paper, for which it suffices to note that an auxiliary assumption along the lines suggested by Meiser and Klauer could perhaps help to make the modular working memory model compatible with the present data.

Of the two models that can accommodate the basic valence effect without the addition of auxiliary assumptions, Cowan's $(1995,1999)$ conception of working memory seems more compatible with the pattern of results obtained 
in the present experiments. In short, rehearsed target elements represent the focus of attention. Valent distractors may automatically attract attention, thereby recruiting processing resources away from the currently attended object representations, which reduces their activation levels and, hence, the probability of successful recall.

As a side note, it may be worth mentioning that from the perspective of this model the traditional notion of an "unattended speech effect" (e.g., Baddeley \& Salamé, 1986; Salamé \& Baddeley, 1982, 1987) makes no sense. Distractor words are task irrelevant by definition, but as changing-state distractors they attract a certain amount of attention (Cowan, 1995, 1999), which results in impaired recall performance. Thus, distractor stimuli are never "unattended" in any strict sense. Of the distractors, those that are behaviorally significant can be assumed to attract more attention away from the primary task (see, e.g., Treisman, 1964). Valent distractors provide significant information about the person herself or about the state of the environment that needs to be attended to, which is why their attention-grabbing effect can be expected to be more pronounced (Pratto, 1994; Pratto \& John, 1991; Wentura et al., 2000). In other words, the processing of affective content - particularly negative other-relevant stimuliautomatically alerts the cognitive system to redirect processing resources to the behavioral demands that are signaled by the valent stimuli. The present results extend previous findings gathered in the domain of perception to the domain of memory processes, indicating that affective interrupt effects have a basic and far-reaching effect on cognitive processing. These findings cannot be explained merely by the assumption that affective valence is processed automatically. Instead, detection of a valent stimulus has more far-reaching consequences involving an interruption of ongoing processing, a redirection of attention to behaviorally relevant information, and the triggering of related action schemas (see Bargh, 1997; Simon, 1967; Wentura \& Rothermund, 2003).

The feature model (Neath, 2000) also seems to be able to account for the basic valence effect on serial recall by treating attentional distraction that is automatically triggered by the processing of valent distractors analogously to the requirement to produce sounds in an articulatory suppression condition. In both cases, appropriately adjusting the attentional parameter of the model would lead to an overall performance decrement.

One problem for the feature model is the interaction between irrelevant speech and serial position observed in both experiments. The model predicts a uniform performance decrement when irrelevant auditory distractors accompany the task of memorizing visually presented target words relative to a silent control condition, but this clearly was not the case. However, two qualifying aspects must be mentioned. First, the feature model is the only computational model considered here, and it is rejected as incompatible with the observed data because it makes a prediction with respect to which other, verbally formulated models are simply silent. Second, although the interaction between irrelevant speech and serial position observed here and in other experiments from our lab (Buchner, Irmen, \& Erdfelder, 1996) is problematic for the feature model, the empirical situation pertaining to the interaction between irrelevant speech and serial position is inconsistent (see Neath, 2000) so that more evidence is needed before a firm judgment on this issue can be reached.

In conclusion, the present results are parallel to those reported by Elliott (2002) from a developmental study in showing that attention plays a role in the maintenance of information in working memory. Models of working memory need to take that into account.

\section{REFERENCES}

BADDEley, A. D. (1986). Working memory. Oxford: Oxford University Press, Clarendon Press.

BadDeley, A. D. (1996). The concept of working memory. In S. E. Gathercole (Ed.), Models of short-term memory (pp. 1-27). Hove, U.K.: Psychology Press.

BAdDELEY, A. D., \& LogIe, R. H. (1999). Working memory: The multiplecomponent model. In A. Miyake \& P. Shah (Eds.), Models of working memory: Mechanisms of active maintenance and executive control (pp. 28-61). New York: Cambridge University Press.

BadDeley, A. D., \& Salamé, P. (1986). The unattended speech effect: Perception or memory? Journal of Experimental Psychology: Learning, Memory, \& Cognition, 12, 525-529.

Banbury, S. P., Tremblay, S., Macken, W. J., \& Jones, D. M. (2001). Auditory distraction and short-term memory: Phenomena and practical implications. Human Factors, 43, 12-29.

BARGH, J. A. (1997). The automaticity of everyday life. In R. S. J. Wyer (Ed.), Advances in social cognition (Vol. 10, pp. 1-61). Mahwah, NJ: Erlbaum.

BROADBENT, D. E. (1983). Recent advances in understanding performance in noise. In Noise as a public health problem: Proceedings of the Fourth International Congress (pp. 719-738). Milano: Edizioni Tecniche a cura del Centro Ricerche e Studi Amplifon.

Buchner, A., Faul, F., \& Erdfelder, E. (1996). G Power: A priori, post-hoc, and compromise power analyses for the Macintosh (Version 2.1.2) [Computer program]. Düsseldorf: Heinrich-Heine-Universität. (Available at http://www.psycho.uni-duesseldorf.de/aap/projects/ gpower/)

BUCHNER, A., IrMEN, L., \& ERDFELdER, E. (1996). On the irrelevance of semantic information for the "irrelevant speech" effect. Quarterly Journal of Experimental Psychology: Human Experimental Psychology, 49A, 765-779.

CENTRE FOR LEXICAL INFORMATION (1991). The CELEX lexical database: German version 2.0 [CD-ROM]. Nijmegen, The Netherlands: Centre for Lexical Information, Max Planck Institute for Psycholinguistics.

COHEN, J. (1977). Statistical power analysis for the behavioral sciences (rev. ed.). Hillsdale, NJ: Erlbaum.

Colle, H. A., \& Welsh, A. (1976). Acoustic masking in primary memory. Journal of Verbal Learning \& Verbal Behavior, 15, 17-32.

Cowan, N. (1995). Attention and memory: An integrated framework. New York: Oxford University Press.

Cowan, N. (1999). An embedded-processes model of working memory. In A. Miyake \& P. Shah (Eds.), Models of working memory: Mechanisms of active maintenance and executive control (pp. 62-101). New York: Cambridge University Press.

ELLiott, E. M. (2002). The irrelevant-speech effect and children: Theoretical implications of developmental change. Memory \& Cognition, 30, 478-487.

ERDFElder, E., FAul, F., \& Buchner, A. (1996). G•POWER: A general power analysis program. Behavior Research Methods, Instruments, \& Computers, 28, 1-11. 
Hager, W., Mecklenbräuker, S., Möller, H., \& Westermann, R. (1985). Emotionsgehalt, Bildhaftigkeit, Konkretheit und Bedeutungshaltigkeit von 580 Adjektiven: Ein Beitrag zur Normierung und zur Prüfung einiger Zusammenhangshypothesen [Emotionality, imagery, concreteness, and meaningfulness for 580 adjectives: Norm values and examination of some hypotheses concerning the different variables]. Archiv für Psychologie, 137, 75-97.

JONES, D. M. (1993). Objects, streams, and threads of auditory attention. In A. D. Baddeley \& L. Weiskrantz (Eds.), Attention, selection, awareness, and control: A tribute to Donald Broadbent (pp. 87-104). Oxford: Oxford University Press.

Jones, D. M., Beaman, C. P., \& Macken, W. J. (1996). The objectoriented episodic record model. In S. E. Gathercole (Ed.), Models of short-term memory (pp. 209-237). Hove, U.K.: Psychology Press.

Jones, D. M., \& MACKEN, W. J. (1993). Irrelevant tones produce an irrelevant speech effect: Implications for phonological coding in working memory. Journal of Experimental Psychology: Learning, Memory, \& Cognition, 19, 369-381.

JoNES, D. M., MACKEN, W. J., \& Murray, A. C. (1993). Disruption of visual short-term memory by changing-state auditory stimuli: The role of segmentation. Memory \& Cognition, 21, 318-328.

Jones, D. M., \& TREmbLAY, S. (2000). Interference in memory by process or content? A reply to Neath (2000). Psychonomic Bulletin \& Review, 7, 550-558.

Klatte, M., \& HellbrücK, J. (1993). Der "Irrelevant Speech Effect": Wirkungen von Hintergrundschall auf das Arbeitsgedächtnis [The "irrelevant speech effect": Effects of background sound on working memory]. Zeitschrift für Lärmbekämpfung, 40, 91-98.

Meiser, T., \& KLAUER, K. C. (1999). Working memory and changingstate hypothesis. Journal of Experimental Psychology: Learning, Memory, \& Cognition, 25, 1272-1299.

Möller, H., \& HaGer, W. (1991). Angenehmheit (P), Bedeutungshaltigkeit $\left(\mathrm{m}^{\prime}\right)$, Bildhaftigkeit (I) und Konkretheit (C) von $452 \mathrm{Ad}-$ jektiven: Ein Beitrag zur Normierung [Concreteness (C), imagery (I), meaningfulness $\left(\mathrm{m}^{\prime}\right)$, and pleasantness $(\mathrm{P})$ ratings for 452 German adjectives]. Sprache \& Kognition, 10, 39-51.

NaIRNe, J. S. (1990). A feature model of immediate memory. Memory \& Cognition, 18, 251-269.

NeATH, I. (2000). Modeling the effects of irrelevant speech on memory. Psychonomic Bulletin \& Review, 7, 403-423.
Neely, C. B., \& LeCompte, D. C. (1999). The importance of semantic similarity to the irrelevant speech effect. Memory \& Cognition, 27, 37-44.

PEETERS, G. (1983). Relational and informational patterns in social cognition. In W. Doise \& S. Moscovici (Eds.), Current issues in European social psychology (Vol. 1, pp. 201-237). Cambridge: Cambridge University Press.

Pratto, F. (1994). Consciousness and automatic evaluation. In P. M. Niedenthal \& S. Kitayama (Eds.), The heart's eye: Emotional influences in perception and attention (pp. 115-143). San Diego: Academic Press.

Pratto, F., \& John, O. P. (1991). Automatic vigilance: The attentiongrabbing power of negative social information. Journal of Personality \& Social Psychology, 61, 380-391.

SALAMÉ, P., \& BADDELEY, A. D. (1982). Disruption of short-term memory by unattended speech: Implications for the structure of working memory. Journal of Verbal Learning \& Verbal Behavior, 21, 150-164.

Salamé, P., \& BadDEley, A. D. (1987). Noise, unattended speech and short-term memory. Ergonomics, 30, 1185-1194.

Salamé, P., \& BAdDELEY, A. D. (1989). Effects of background music on phonological short-term memory. Quarterly Journal of Experimental Psychology, 41A, 107-122.

SimON, H. A. (1967). Motivational and emotional controls of cognition. Psychological Review, 74, 29-39.

Treisman, A. M. (1964). Selective attention in man. British Medical Bulletin, 20, 12-16.

WENTURA, D., \& Rothermund, K. (2003). The "meddling-in" of affective information: A general model of automatic evaluation effects. In J. Musch \& K. C. Klauer (Eds.), The psychology of evaluation: Affective processes in cognition and emotion (pp. 51-86). Mahwah, NJ: Erlbaum.

Wentura, D., Rothermund, K., \& BaK, P. (2000). Automatic vigilance: The attention-grabbing power of approach- and avoidancerelated social information. Journal of Personality \& Social Psychology, 78, 1024-1037.

\section{NOTE}

1.The power calculations were conducted using the $\mathrm{G} \cdot$ Power program (Buchner, Faul, \& Erdfelder, 1996; Erdfelder, Faul, \& Buchner, 1996). 


\section{APPENDIX}

Table A1

Properties of the Distractor Words Used in the Present Experiments

\begin{tabular}{lllll}
\hline \multicolumn{1}{c}{ Neutral } & \multicolumn{1}{c}{$\begin{array}{c}\text { Positive } \\
\text { Possessor-Relevant }\end{array}$} & \multicolumn{1}{c}{$\begin{array}{c}\text { Positive } \\
\text { Other-Relevant }\end{array}$} & \multicolumn{1}{c}{$\begin{array}{c}\text { Negative } \\
\text { Possessor-Relevant }\end{array}$} & \multicolumn{1}{c}{$\begin{array}{c}\text { Negative } \\
\text { Other-Relevant }\end{array}$} \\
\hline $\begin{array}{llll}\text { neugierig (curious) } \\
\text { anstrengend (wearisome) }\end{array}$ & $\begin{array}{l}\text { kreativ (creative) } \\
\text { unbeschwert (jauntily) }\end{array}$ & $\begin{array}{l}\text { warmherzig (warm-hearted) } \\
\text { einfühlsam (sensitive) }\end{array}$ & $\begin{array}{l}\text { apathisch (apathetic) } \\
\text { verbittert (embittered) }\end{array}$ & $\begin{array}{l}\text { heimtückisch (perfidious) } \\
\text { unfreundlich (harsh) }\end{array}$ \\
anspruchslos (undemanding) & ausdauernd (persevering) & rücksichtsvoll (amicable) & entmutigt (demoralized) & bösartig (malignant) \\
bedächtig (deliberate) & einfallsreich (inventive) & aufrichtig (honest) & einfallslos (unimaginative) & rücksichtslos (ruthless) \\
kompliziert (complicated) & selbstsicher (self-confident) & hilfsbereit (cooperative) & unglücklich (miserable) & aufdringlich (obtrusive) \\
wählerisch (choosey) & vielseitig (versatile) & liebevoll (loving) & verzweifelt (desperate) & aggressiv (aggressive) \\
geschäftig (busy) & flexibel (flexible) & tolerant (tolerant) & ohnmächtig (helpless) & unsozial (antisocial) \\
\hline
\end{tabular}

\begin{tabular}{|c|c|c|c|c|c|}
\hline \multicolumn{6}{|c|}{ Valence } \\
\hline & 2 & 69 & 64 & -65 & -77 \\
\hline & -7 & 50 & 68 & -68 & -60 \\
\hline & 2 & 52 & 53 & -57 & -83 \\
\hline & 7 & 58 & 74 & -54 & -62 \\
\hline & -13 & 55 & 65 & -60 & -57 \\
\hline & 9 & 62 & 81 & -63 & -52 \\
\hline & 4 & 56 & 68 & -53 & -56 \\
\hline Average: & 1 & 57 & 68 & -60 & -64 \\
\hline \multicolumn{6}{|c|}{ Concreteness } \\
\hline & 56 & 55 & 70 & 54 & 39 \\
\hline & 61 & 43 & 56 & 51 & 64 \\
\hline & 34 & 47 & 43 & 43 & 35 \\
\hline & 52 & 38 & 46 & 23 & 48 \\
\hline & 47 & 65 & 59 & 58 & 62 \\
\hline & 54 & 46 & 74 & 60 & 68 \\
\hline & 60 & 32 & 63 & 68 & 35 \\
\hline Average: & 52 & 47 & 59 & 51 & 50 \\
\hline \multicolumn{6}{|c|}{ Frequency } \\
\hline & 96 & 7 & 11 & 5 & 18 \\
\hline & 38 & 12 & 4 & 31 & 38 \\
\hline & 11 & 8 & 14 & 11 & 10 \\
\hline & 1 & 20 & 70 & 4 & 62 \\
\hline & 155 & 22 & 24 & 97 & 3 \\
\hline & 9 & 282 & 50 & 149 & 220 \\
\hline & 14 & 38 & 32 & 67 & 5 \\
\hline Average: & 46 & 56 & 29 & 52 & 51 \\
\hline
\end{tabular}

Note-English translations of the German distractor words are in parentheses. Values in the valence (ratings on a scale from -100 to 100), concreteness (ratings on a scale from 0 to 100), and frequency (relative to the CELEX text body of about 6 million words) subtables refer to words with the same cell coordinates in the topmost subtable (e.g., the valence score of "aufrichtig" [honest] is 74).

(Manuscript received October 15, 2003;

revision accepted for publication January 8, 2004.) 